\title{
Article \\ Thickness Impact on the Morphology, Strain Relaxation and Defects of Diamond Heteroepitaxially Grown on $\mathrm{Ir} / \mathrm{Al}_{2} \mathrm{O}_{3}$ Substrates
}

\author{
Ruozheng Wang ${ }^{1,+}\left(\mathbb{D}\right.$, Fang Lin ${ }^{1,+}$, Qiang Wei ${ }^{1}$, Gang Niu ${ }^{2, *}$ and Hong-Xing Wang ${ }^{1, *(\mathbb{D})}$ \\ 1 Ministry Education Key Laboratory of Physical Electronics and Devices, School of Electronic Science and \\ Engineering, Xi'an Jiaotong University, Xi'an 710049, China; wangrz@xjtu.edu.cn (R.W.); \\ leaf-lin@xjtu.edu.cn (F.L.); wbgwei@mail.xjtu.edu.cn (Q.W.) \\ 2 Key Laboratory of the Ministry of Education \& International Center for Dielectric Research, School of \\ Electronic Science and Engineering, Xi'an Jiaotong University, Xi'an 710049, China \\ * Correspondence: gangniu@xjtu.edu.cn (G.N.); hxwangen@mail.xjtu.edu.cn (H.-X.W.) \\ $\dagger$ These authors contributed equally to this study and share the first authorship.
}

check for updates

Citation: Wang, R.; Lin, F.; Wei, Q.; Niu, G.; Wang, H.-X. Thickness Impact on the Morphology, Strain Relaxation and Defects of Diamond Heteroepitaxially Grown on $\mathrm{Ir} / \mathrm{Al}_{2} \mathrm{O}_{3}$ Substrates. Materials 2022, 15, 624 https://doi.org/10.3390/ma15020624

Academic Editor: Cyril Popov

Received: 9 December 2021

Accepted: 12 January 2022

Published: 14 January 2022

Publisher's Note: MDPI stays neutral with regard to jurisdictional claims in published maps and institutional affiliations.

Copyright: (C) 2022 by the authors. Licensee MDPI, Basel, Switzerland. This article is an open access article distributed under the terms and conditions of the Creative Commons Attribution (CC BY) license (https:// creativecommons.org/licenses/by/ $4.0 /)$.

\begin{abstract}
This paper investigates the formation and propagation of defects in the heteroepitaxial growth of single-crystal diamond with a thick film achieving $500 \mu \mathrm{m}$ on $\operatorname{Ir}(001) / \mathrm{Al}_{2} \mathrm{O}_{3}$ substrate. The growth of diamond follows the Volmer-Weber mode, i.e., initially shows the islands and subsequently coalesces to closed films. The films' strain imposed by the substrate gradually relaxed as the film thickness increased. It was found that defects are mainly located at the diamond/Ir interface and are then mainly propagated along the [001] direction from the nucleation region. Etching pits along the [001] direction formed by $\mathrm{H}_{2} / \mathrm{O}_{2}$ plasma treatment were used to show defect distribution at the diamond $/ \mathrm{Ir} / \mathrm{Al}_{2} \mathrm{O}_{3}$ interface and in the diamond bulk, which revealed the reduction of etching pit density in diamond thick-film surface. These results show the evident impact of the thickness on the heteroepitaxially grown diamond films, which is of importance for various device applications.
\end{abstract}

Keywords: heteroepitaxial diamond; film thickness; morphology; TEM; etching pits

\section{Introduction}

Diamond is a promising material for high power and high frequency electronic devices owing to its excellent material properties, e.g., ultra-wide band gap (5.5 eV), high thermal conductivity $(2200 \mathrm{~W} / \mathrm{m} \cdot \mathrm{K})$, high breakdown voltage $\left(10^{7} \mathrm{~V} / \mathrm{cm}\right)$, high electron and hole mobility $\left(4500 \mathrm{~cm}^{2} / \mathrm{V} \cdot \mathrm{s}\right.$ and $\left.3800 \mathrm{~cm}^{2} / \mathrm{V} \cdot \mathrm{s}\right)$, and low dielectric constant (5.7) [1-5]. Heteroepitaxially grown single-crystal diamond is considered a promising method for realizing large-area diamond substrate [6]. Diamond grown on an iridium (Ir) buffer layer has been proved good crystallinity [7-9]. However, due to the difference of lattice constants between diamond and Ir, the crystal lattice mismatch, strains and defects are generated from diamond/Ir interface [10-13], leading to the higher defect density of heteroepitaxial diamond compared with homoepitaxial samples [14-16]. Therefore, it is essential to understand the origin and propagation of defects during the different growth stages of heteroepitaxial diamond, which could make great significance for the preparation and practicability of large-area, high-quality diamond substrate.

In this work, heteroepitaxial diamond on $\mathrm{Ir} / \mathrm{Al}_{2} \mathrm{O}_{3}$ substrates has been performed by MPCVD (microwave plasma chemical vapor deposition) with different thickness. Methods such as scanning electron microscope (SEM), atomic force microscope (AFM) and X-ray diffraction (XRD) are introduced to analyze the morphology and crystallinity of initial diamond growth. Then, transmission electron microscope (TEM) is used to observe the cross-section of the diamond/Ir (001) interface which is fabricated by FIB. The etching pit distribution on the surface of a heteroepitaxial diamond along the (001) direction is detected by SEM. It is clear that the etching pit density at the diamond/Ir interface is larger due to lattice mismatch. 
With the increase in film thickness, the diamond is coalesced to the closed film combined with strain relaxation so that the etching pit density reduces a lot. This research could provide important evidence for the understanding of the dislocation distribution of heteroepitaxial diamond thick films, both at the interface and in the film bulk.

\section{Experimental}

A $300 \mathrm{~nm}$ Ir (001) film was deposited on $10 \mathrm{~mm} \times 10 \mathrm{~mm} \mathrm{Al}_{2} \mathrm{O}_{3}$ [11-20] substrate by magnetron sputtering (ACS-4000-C4, ULVAC, Japan). The deposition power was $75 \mathrm{~W}$, the Ar flow was $50 \mathrm{sccm}$, and the deposition rate was about $2 \mathrm{~nm} / \mathrm{min}$. Then, the (001)-oriented diamond was fabricated on $\mathrm{Ir} / \mathrm{Al}_{2} \mathrm{O}_{3}$ substrate using bias enhanced nucleation (BEN) method by direct current chemical vapor deposition (DC-CVD, made by ourselves). The total gas flow rate was $500 \mathrm{sccm}$, the $\mathrm{CH}_{4} / \mathrm{H}_{2}$ flow ratio was $5 \%$, the gas pressure was 25 torr, the direct current was $1.5 \mathrm{~A}$, the temperature was $900{ }^{\circ} \mathrm{C}$, a bias voltage on substrate of $350 \mathrm{~V}$, and the duration time was $150 \mathrm{~s}$ [17]. After BEN, the diamond nuclei were formed on the Ir surface. $\mathrm{Ir} / \mathrm{Al}_{2} \mathrm{O}_{3}$ nucleated substrates were put in MPCVD (AX5250S Seki Technotron Corp., Tokyo, Japan) for epitaxial diamond growth. The deposition power was $2500 \mathrm{~W}$, the chamber pressure was 90 torr, the temperature was $950{ }^{\circ} \mathrm{C}$, the total gas flow rate was $500 \mathrm{sccm}$, the $\mathrm{CH}_{4} / \mathrm{H}_{2}$ flow ratio was $5 \%$, and the $\mathrm{N}_{2} / \mathrm{H}_{2}$ flow ratio was $0.03 \%$. SEM (ZEISS, Crossbeam 540, Jena, Germany), AFM (SPI, 3800-SPA-400, Osaka, Japan) and XRD (Panalytical, X'Pert PROMRD, Almelo, The Netherlands) were used to analyze the effect of thickness on the diamond surface morphology and crystallinity. Furthermore, four samples were selected to grow 5 mins, 10 mins, 20 mins and 40 mins, respectively, which were defined as sample 1 to sample $4\left(S_{1}\right.$ to $\left.S_{4}\right)$. Finally, after $100 \mathrm{~h}$ of growth, the $500 \mu \mathrm{m}$ of diamond thick film was obtained (sample $5, S_{5}$ ).

Then, $\mathrm{S}_{5}$ was cut and polished along (110) plane with a roughness nearly $2 \mathrm{~nm}$ [18]. After that, the sample was etched by $\mathrm{H}_{2} / \mathrm{O}_{2}$ plasma at the gas flow of $500 / 5 \mathrm{sccm}$, the temperature of $900{ }^{\circ} \mathrm{C}$, and the duration time of $30 \mathrm{~min}$. Etch pits appeared where the dislocations emerged at the crystal surface [19,20]. TEM (JEOL, JEM 2100 F, Tokyo, Japan) was used to observe the interface of diamond/Ir. SEM was applied to observe the surface and cross-section of heteroepitaxial diamond. Different regions located in the cross-section of $\mathrm{S}_{5}$ were tested by Raman spectra (Renishaw, inVia, Banbury, UK).

\section{Results and Discussion}

Figure 1 showed the variation of heteroepitaxy diamond morphology observed by SEM. In Figure 1a, diamond epitaxial layers contained with a lot of highly oriented diamond dots had appeared on the $\mathrm{Ir} / \mathrm{Al}_{2} \mathrm{O}_{3}$ substrate. Then, the adjacent diamond dots gradually combined to form an island grains distribution (shown in Figure 1b). Moreover, the islandshaped grains had gradually coalesced, becoming a closed thin-film structure, only few areas represented grain gaps that were not entirely coalesced (shown in Figure 1c). The diamond film finally formed a complete closed film as shown in Figure 1d, which provided a precondition for the thick-film growth of $S_{5}$. 

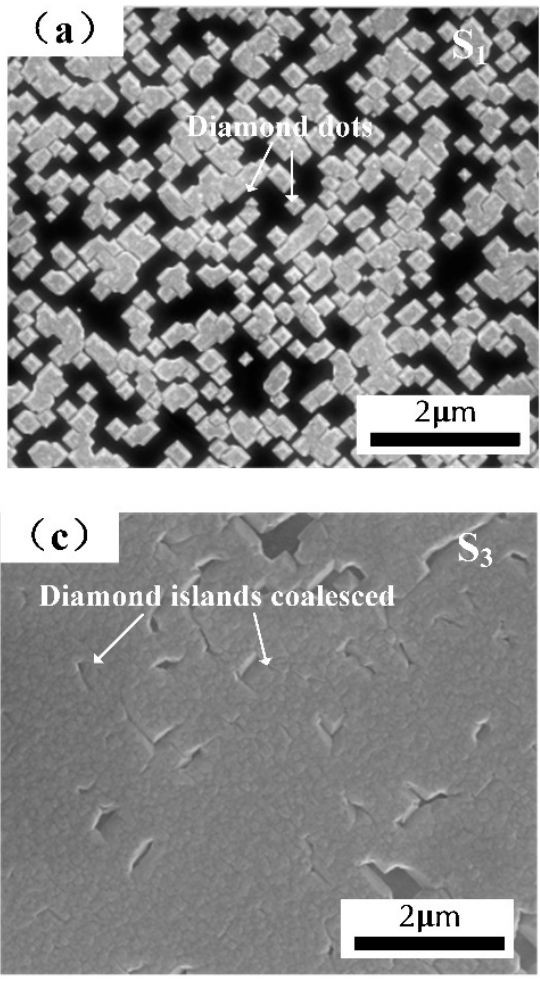
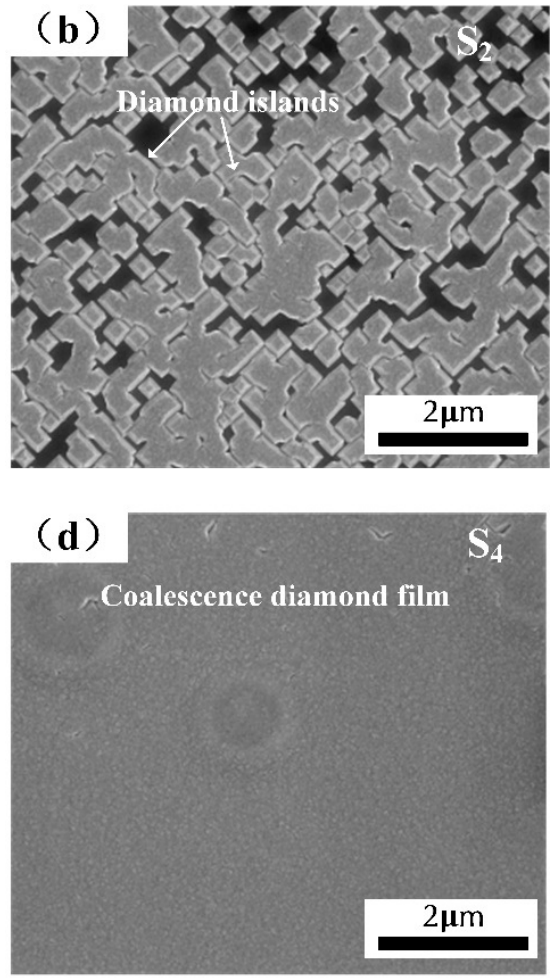

Figure 1. SEM observation of diamond at different growth time after nucleation. (a) $5 \mathrm{~min}$; (b) $10 \mathrm{~min}$; (c) $20 \mathrm{~min}$; (d) $40 \mathrm{~min}$.

AFM with the range of $2 \mu \mathrm{m} \times 2 \mu \mathrm{m}$ was applied to observe the film roughness of $S_{1}$ to $S_{4}$, which is described in Figure 2. Figure 2a shows that the surface of diamond dots presented scattered square humps with a grain size of about $120 \mathrm{~nm}$ and thickness of about $15 \mathrm{~nm}$. For the $S_{2}$ sample, the grain size showed an obvious increase, with a grain size of about $400 \mathrm{~nm}$ and a thickness of about $200 \mathrm{~nm}$ (shown in Figure 2b), which attributed to island growth mode. Then, the image of $S_{3}$ showed that the fluctuation of the film decreased rapidly, and the height steps reduced to about $10 \mathrm{~nm}$, representing the characteristics of closed diamond films (shown in Figure 2c). Lastly, in Figure 2d, the flatness of diamond films was achieved, indicating that the diamond grains have coalesced and have formed a closed film. The root mean square (RMS) roughness of four samples were 4.44, 41.1, 2.05 and $2.37 \mathrm{~nm}$, respectively, reflecting the variation of film morphology during initial diamond growth. We guessed that increase of $\mathrm{S}_{4}$ could possibly be due to the selection of test area, e.g., substrate roughness, non-coalesced film, or impurities adsorbed on the film surface.

Figure 3 represented the XRD rocking curves of diamond (004) orientation at different growth stages. Obviously, there was no diamond (004) characteristics peak in the initial growth stage when heteroepitaxial diamond film is too thin to form a continuous and dense film (corresponded to $S_{1}$ ). Then, with the increase in film thickness, the diamond (004) peak gradually appeared and grew in intensity. Meanwhile, as growth continues, the full widths at half maximum (FWHM) of (004) rocking curves were decreased, at which the FWHM of $\mathrm{S}_{5}$ measured in the (004) direction was 284.4 arcsec, showing a decent crystallinity of heteroepitaxy diamond grown on $\mathrm{Ir} / \mathrm{Al}_{2} \mathrm{O}_{3}$ substrate. 

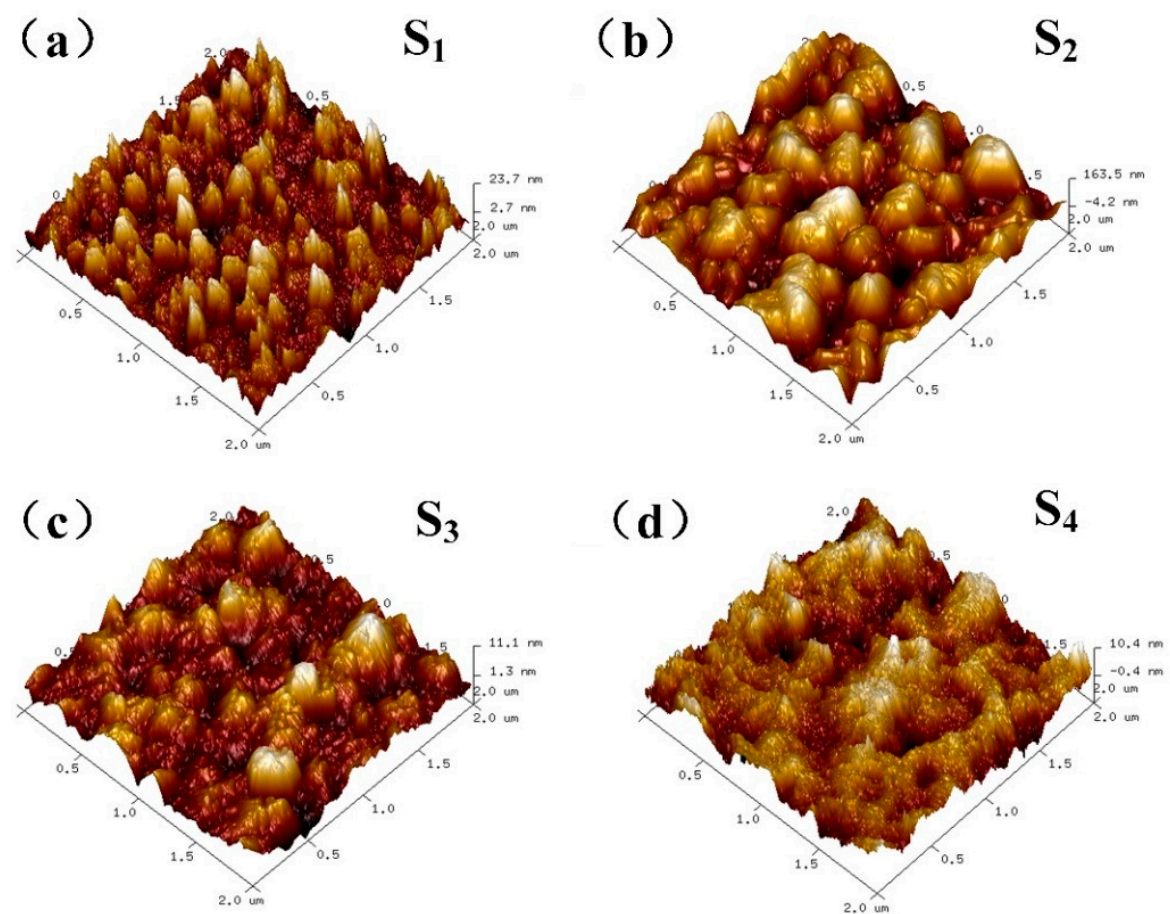

Figure 2. AFM observation of diamond at different growth time after nucleation. (a) $5 \mathrm{~min}$; (b) $10 \mathrm{~min}$; (c) $20 \mathrm{~min}$; (d) $40 \mathrm{~min}$

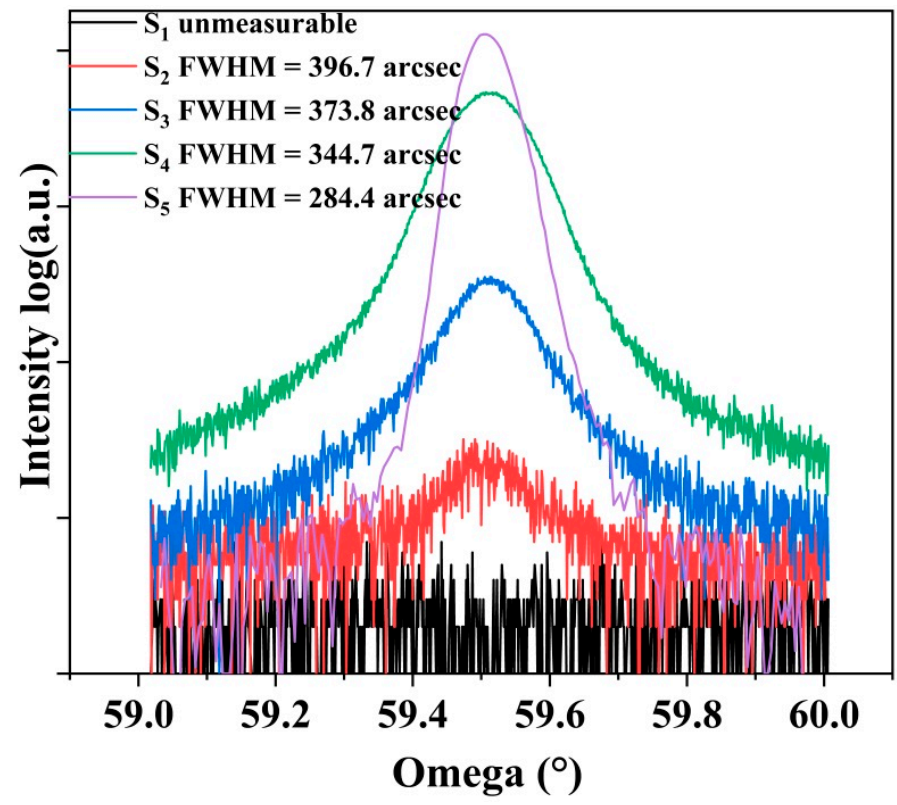

Figure 3. XRD rocking curves of heteroepitaxial diamond at different growth stages after nucleation $\left(\mathrm{S}_{1}\right.$ to $\left.\mathrm{S}_{4}\right)$ and the thick film $\left(\mathrm{S}_{5}\right)$.

As mentioned above, in order to study the propagation of defects in heteroepitaxial diamond, a thick diamond film $\left(S_{5}, 500 \mu \mathrm{m}\right)$ was deposited by MPCVD. TEM was adopted to characterize the cross-section of diamond bulk along [110] zone axis (ZA). The propagation of defects at the diamond/Ir interface was directly observed by a TED mode at $400 \mathrm{kV}$. The sample $(10 \mu \mathrm{m} \times 5 \mu \mathrm{m} \times 100 \mathrm{~nm})$ was prepared on the back of utilizing a focused ion beam (FIB) technology. The bright diamond epitaxial layer and the dark Ir metal layer could be detected in the Figure 4, as well as noticeable dark stripes in the diamond bulk. These shadows revealed that the diamonds gradually converted from single grains into coalesced 
films, as shown in area A in Figure 4. Especially in the regions above Ir layer, there were lots of dislocations with an angle of $45^{\circ}$ along the Ir (001) plane. With the increase in film thickness, diamond grains gradually coalesced, along with dislocations extended to the surface (shown in area B in Figure 4), corresponding to the image that is displayed in Figure $1 \mathrm{~d}$. Selected area diffraction pattern (SADP) images were measured in order to make sure the crystal orientation of the TEM images. The results showed that in the area A near diamond/Ir interface, there were regular spots representing cubic crystal systems in the electron diffraction spots. After the calculation of SADP images, the crystal plane spacing of diamond (2-20) plane was $1.274 \AA$, increased by $1 \%$ compared to standard diamond card $(1.261 \AA)$, which was related to the epitaxial diamond growth from $\mathrm{Ir} / \mathrm{Al}_{2} \mathrm{O}_{3}$ substrate. In addition, the crystal-plane spacing of Ir (2-20) was larger than that of diamond (1.357 $\AA$ ), and two azimuthally broadened diffraction spots can be observed at the SADP of area A, indicating the in-plane disorientation of the initial diamond islands grown on the Ir layer. This means, because of the small disorientation of the Ir buffer, the diamond islands at the very beginning of the growth had a tendency to be textured [21]. As growth continued, such a tendency stopped and the diamond layer followed the single crystalline epitaxial growth. Meanwhile, the asymmetric diffraction spots disappeared in the SADP images at area B and C, and the lattice constants were $1.267 \AA$ and $1.265 \AA$, respectively, which were close to the intrinsic diamond.

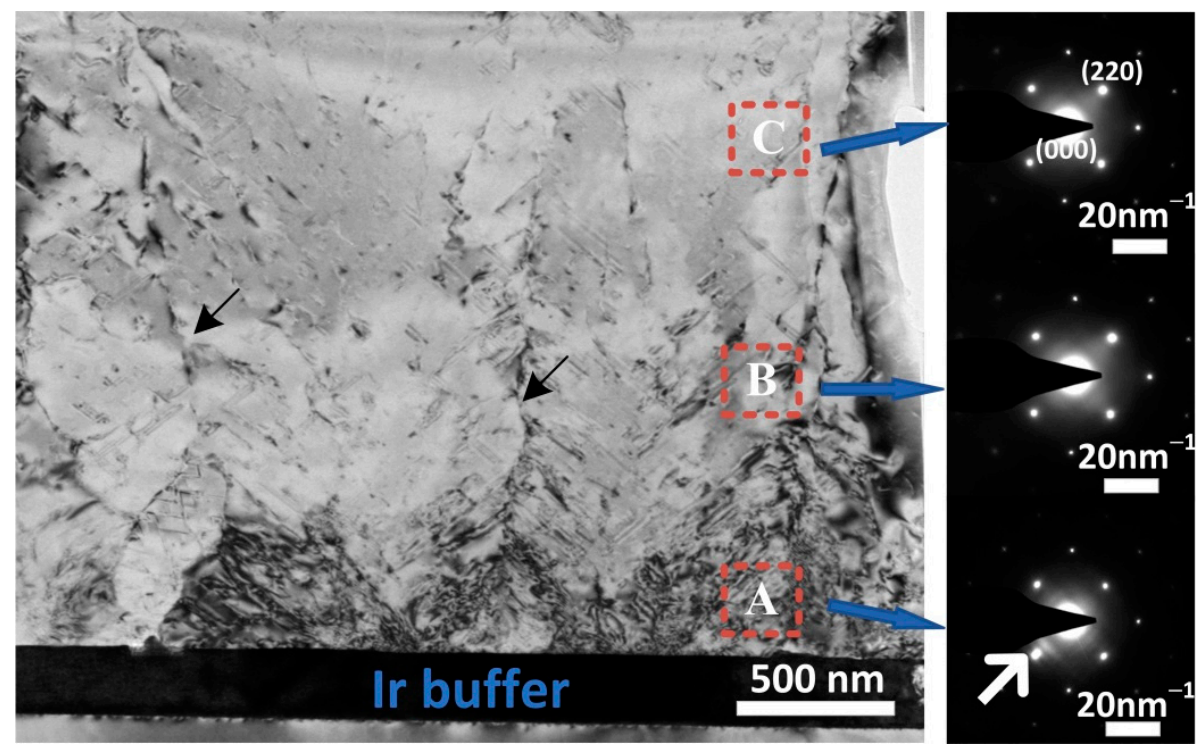

Figure 4. TEM image of heteroepitaxy diamond on $\mathrm{Ir}(001) / \mathrm{Al}_{2} \mathrm{O}_{3}$ substrate along [110] zone axis (area A: near diamond/Ir interface; area B: above the diamond/Ir interface; area C: in the diamond bulk).

Additionally, the morphology of heteroepitaxial diamond after $\mathrm{H}_{2} / \mathrm{O}_{2}$ plasma treatment was observed by SEM. Figure 5a,b showed the etching pit distributions both at the diamond/Ir interface and the film surface along the (001) direction, which represented extensive overlapping rectangles appearance. Some cracks were found in Figure 5a which was attributed to the strain between $\mathrm{Al}_{2} \mathrm{O}_{3}$ substrate and diamond thin film [22], but it has no relationship with the defects since the cracks were formed before $\mathrm{H}_{2} / \mathrm{O}_{2}$ plasma treatment. Moreover, the lower etching pit density was observed on Figure 5b, indicating partial dislocations were annihilated in the epitaxial layer during diamond growth. The shape of etching pits depended on the angle of dislocation terminated at the diamond/Ir surface which could be observed at Figure 1a before [23], illustrating that the propagation of dislocations were mainly along (001) from the nucleation region [24]. 

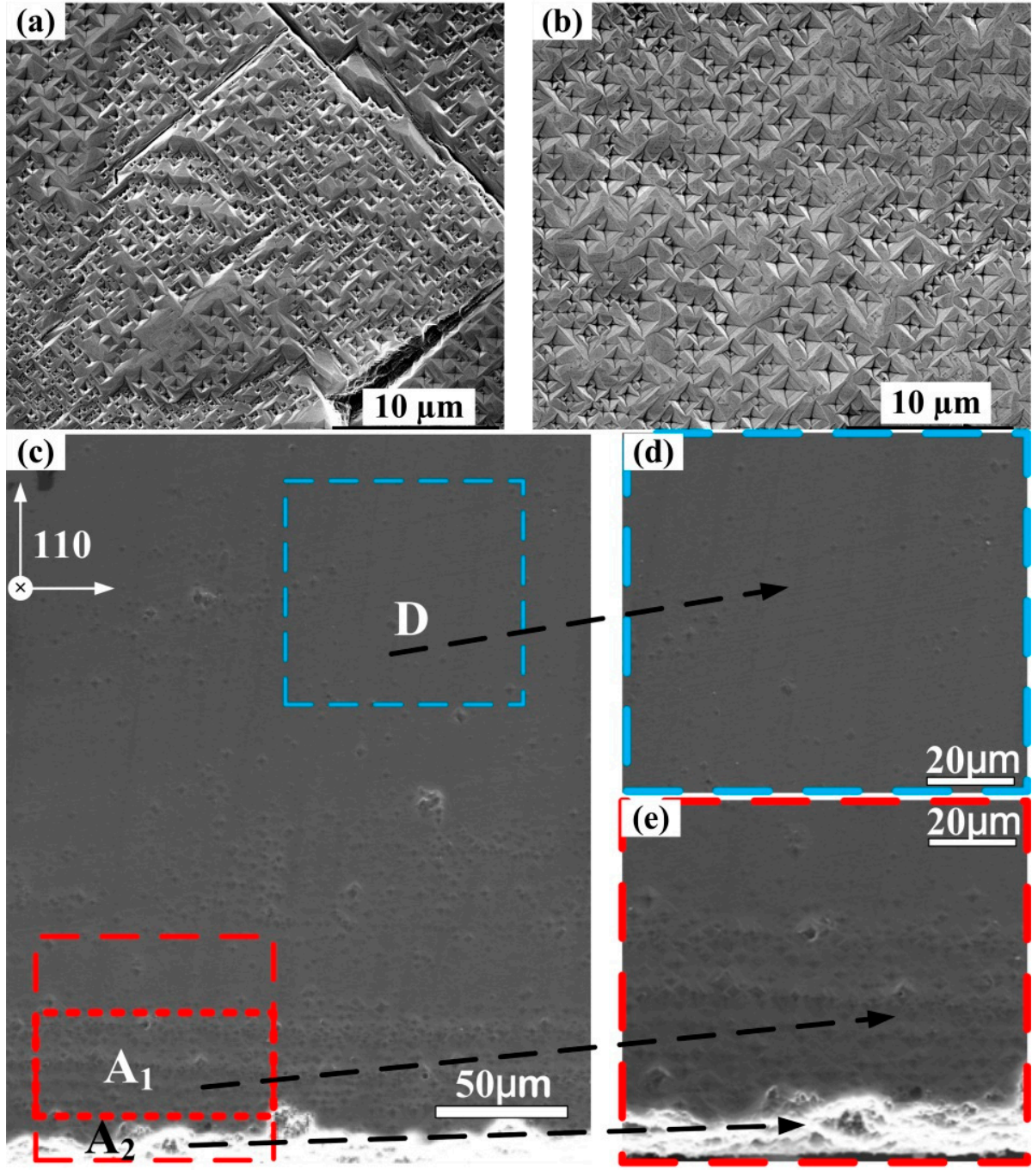

Figure 5. Etching pits of the heteroepitaxial diamond along [001] direction (a) at diamond/Ir interface and (b) at the surface of diamond thick film; Etching pits of heteroepitaxial diamond crosssections along [220] direction (c) the film bulk distributions. (d) the magnification at diamond/Ir interface. (e) the magnification near film surface. $\left(\mathrm{A}_{1}: 20 \mu \mathrm{m}\right.$ above diamond/Ir interface. $\mathrm{A}_{2}$ : at the diamond/Ir interface; D: $200 \mu \mathrm{m}$ above diamond/Ir interface).

Furthermore, etching pits distribution in the cross-section region extending from the interface to diamond bulk was shown in Figure 5c-e. At the diamond/Ir interface, numerous etching pits and rough epitaxial layers were detected, representing the poor crystal quality at grain boundaries (area $\left.\mathrm{A}_{2}\right)$ [24]. Then, as the initial growth continued, especially in the film bulk of $20 \mu \mathrm{m}$ above diamond/Ir interface (area $\mathrm{A}_{1}$ ), a relatively high etching pit density along the (220) direction was obtained. When the thickness of the diamond film exceeded $200 \mu \mathrm{m}$, etching pit density reduced notably due to the improved epitaxial crystallinity (area D). It was clear that the etching pits were not continuously distributed in the whole diamond bulks. We could infer that due to the larger lattice mismatch at diamond $/ \mathrm{Ir} / \mathrm{Al}_{2} \mathrm{O}_{3}$ substrate, a great quantity of etching pits were located at interface. During the growth mode of diamond transition from dispersed islands to coalescence film (shown in Figure 1), the etching rate by $\mathrm{H}_{2} / \mathrm{O}_{2}$ plasma treatment on the film was also changed. Therefore, the heteroepitaxial diamond film had undergone a relaxation process. With the increase in film thickness, the lattice constant of the epitaxial film was close to the diamond (220) standard value (1.265 ̊ vs. $1.261 \AA$ ), and the strain of the film was fully relaxed. The epitaxial layer was formed as high-quality and dense film. 
Then, a Raman spectrum was used to test the diamond characteristics peaks and defects at different positions of the diamond bulk, which is shown in Figure 6. The laser wavelength was $532 \mathrm{~nm}$, and we chose five positions on the cross-section of the diamond bulk, which were 5, 20, 50, 100, $500 \mu \mathrm{m}$ away from the diamond/Ir interface, respectively. A weak first-order diamond characteristic peak $\left(1332 \mathrm{~cm}^{-1}\right)$ could be observed at the position of $5 \mu \mathrm{m}$ above the diamond/Ir interface. However, there were fluorescence peaks related to nitrogen $(\mathrm{N})$ defects in a wide range of $1460 \mathrm{~cm}^{-1}$, the intensity of which exceeded that of the diamond characteristic peaks $[25,26]$. As growth continued, the intensity of the diamond characteristic peak significantly increased, while the nitrogen-related peaks remained stable. This phenomenon depicted that there were a large number of $\mathrm{N}$ vacancies located in grain boundaries during the initial growth of the diamond. Then, the grains coalesced to closed films so that the $\mathrm{N}$ vacancy concentrations kept stable $[27,28]$. Last, the Raman peak width was reduced from $6.27 \mathrm{~cm}^{-1}$ to $5.42 \mathrm{~cm}^{-1}$ with the increase in film thickness, indicating the better crystal quality and lower defects at the heteroepitaxial diamond film surface.

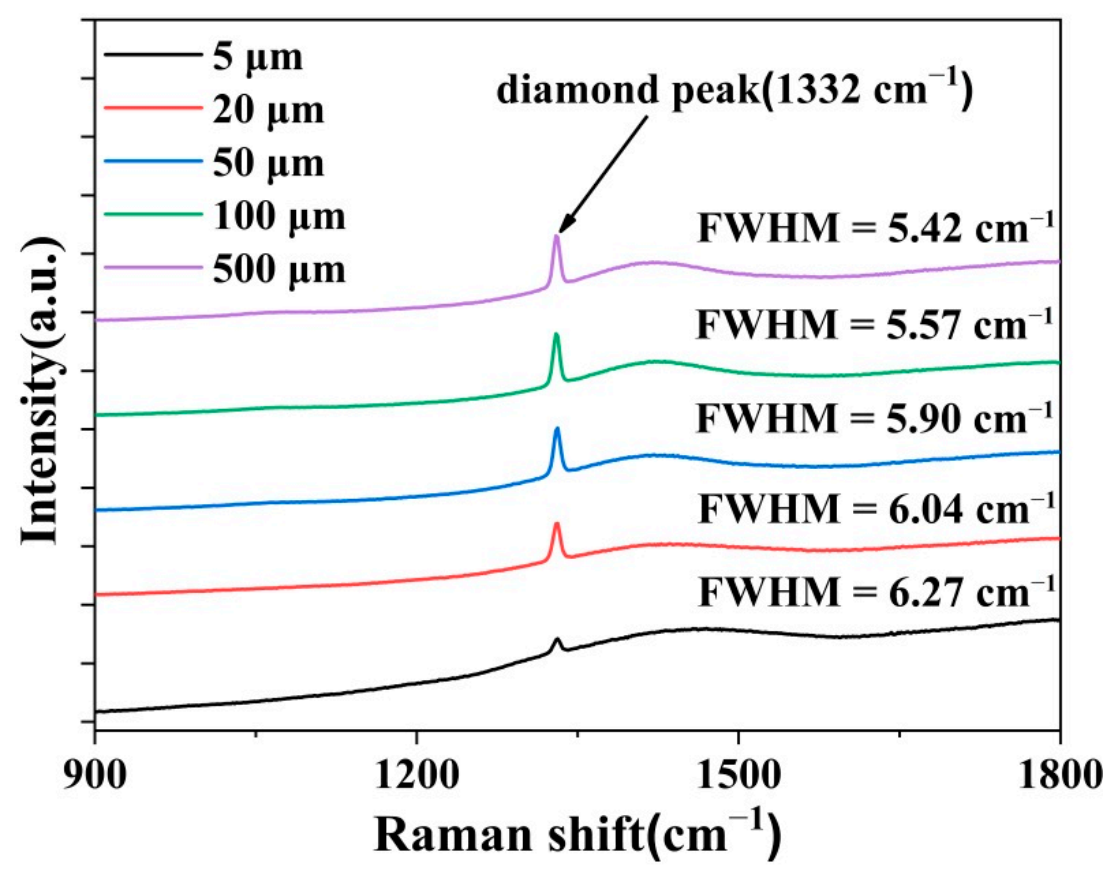

Figure 6. Raman spectra at different diamond cross-section positions above the diamond/Ir interface.

\section{Conclusions}

In summary, the impact of film thickness on heteroepitaxially grown diamond is explored. SEM results show the evolution of diamond morphology from dots, islands, and then coalesced to closed film. AFM results display that the island growth possesses the largest roughness of $41.1 \mathrm{~nm}$, and then a smooth surface with RMS of $2.37 \mathrm{~nm}$ is obtained. XRD rocking curves depict that the decent FWHM of 284.4 arcsec is obtained from the diamond thick film. The dislocations distribution in heteroepitaxial diamond extending from interface to the film bulk is observed by TEM and SEM. Numerous etching pits near the interface owing to the small disorientation of the initial diamond islands grown on the Ir layer. With the coalescence of diamond islands to closed film, the diamond bulk strain is relaxed so that the dislocations are reduced. This study illustrates the generation and evolution of dislocation in the whole heteroepitaxial diamond thick film, which will contribute to promote the quality of heteroepitaxial diamond substrate and electronic devices. 


\begin{abstract}
Author Contributions: Conceptualization, R.W. and Q.W.; Methodology, R.W.; Formal analysis, F.L.; Investigation, F.L.; Data curation, R.W. and Q.W.; Project administration, H.-X.W.; Funding acquisition, G.N. and H.-X.W.; Visualization, R.W.; Writing-original draft, R.W.; Supervision, G.N. and H.-X.W.; Writing-review and editing, G.N. and H.-X.W. All authors have read and agreed to the published version of the manuscript.
\end{abstract}

Funding: This work was supported by the National Key Research and Development Program of China (Grant No. 2018YFE0125900), National Natural Science Foundation of China (Grant No. 61627812, 61804122), and the Key R\&D Program of Shaanxi Province of China (No. 2020GY-271).

Institutional Review Board Statement: Not applicable.

Informed Consent Statement: Not applicable.

Data Availability Statement: Data available on request due to restrictions, e.g., privacy or ethical.

Conflicts of Interest: The authors declare no conflict of interest.

\title{
References
}

1. Isberg, J.; Hammersberg, J.; Johansson, E.; Twitchen, D.J.; Whitehead, A.J. High Carrier Mobility in Single-Crystal PlasmaDeposited Diamond. Science 2002, 297, 1670-1673. [CrossRef]

2. Saha, N.C.; Kim, S.W.; Oishi, T.; Kawamata, Y.; Koyama, K.; Kasu, M. 345-MW/cm² 2608-V NO p-Type Doped Diamond MOSFETs with an AlO Passivation Overlayer on Heteroepitaxial Diamond. IEEE Electron Device Lett. 2021, 42, 903-906. [CrossRef]

3. Matsumae, T.; Kurashima, Y.; Umezawa, H.; Mokuno, Y.; Takagi, H. Room-temperature bonding of single-crystal diamond and Si using $\mathrm{Au} / \mathrm{Au}$ atomic diffusion bonding in atmospheric air. Microelectron. Eng. 2018, 195, 68-73. [CrossRef]

4. Donato, N.; Rouger, N.; Pernot, J.; Longobardi, G.; Udrea, F. Diamond power devices: State of the art, modelling, figures of merit and future perspective. J. Phys. D Appl. Phys. 2020, 53, 093001. [CrossRef]

5. May, P.W. Materials science: The new diamond age? Science 2008, 319, 1490-1491. [CrossRef]

6. Schreck, M.; Gsell, S.; Brescia, R.; Fischer, M. Ion bombardment induced buried lateral growth: The key mechanism for the synthesis of single crystal diamond wafers. Sci. Rep. 2017, 7, 44462. [CrossRef] [PubMed]

7. Schreck, M.; Roll, H.; Stritzker, B. Diamond/Ir/SrTiO 3 : A material combination for improved heteroepitaxial diamond films. Appl. Phys. Lett. 1999, 74, 650-652. [CrossRef]

8. Ohtsuka, K.; Fukuda, H.; Suzuki, K.; Sawabe, A. Fabrication of epitaxial diamond thin film on iridium. Jpn. J. Appl. Phys. Part 2 Lett. 1997, 36, L1214-L1216. [CrossRef]

9. Aida, H.; Kim, S.W.; Ikejiri, K.; Kawamata, Y.; Koyama, K.; Kodama, H.; Sawabe, A. Fabrication of freestanding heteroepitaxial diamond substrate via micropatterns and microneedles. Appl. Phys. Express 2016, 9, 035504. [CrossRef]

10. Sawabe, A.; Fukuda, H.; Suzuki, T.; Ikuhara, Y.; Suzuki, T. Interface between CVD diamond and iridium films. Surf. Sci. 2000, 467, 845-849. [CrossRef]

11. Gsell, S.; Bauer, T.; Goldfuß, J.; Schreck, M.; Stritzker, B. A route to diamond wafers by epitaxial deposition on silicon via iridium/yttria-stabilized zirconia buffer layers. Appl. Phys. Lett. 2004, 84, 4541-4543. [CrossRef]

12. Fischer, M.; Gsell, S.; Schreck, M.; Brescia, R.; Stritzker, B. Preparation of 4-inch Ir/YSZ/Si(001) substrates for the large-area deposition of single-crystal diamond. Diam. Relat. Mater. 2008, 17, 1035-1038. [CrossRef]

13. Gsell, S.; Fischer, M.; Brescia, R.; Schreck, M.; Huber, P.; Bayer, F.; Stritzker, B.; Schlom, D.G. Reduction of mosaic spread using iridium interlayers: A route to improved oxide heteroepitaxy on silicon. Appl. Phys. Lett. 2007, 91, 89-92. [CrossRef]

14. Tallaire, A.; Brinza, O.; Mille, V.; William, L.; Achard, J. Reduction of Dislocations in Single Crystal Diamond by Lateral Growth over a Macroscopic Hole. Adv. Mater. 2017, 29, 1-5. [CrossRef] [PubMed]

15. Umezawa, H.; Kato, Y.; Watanabe, H.; Omer, A.M.M.; Yamaguchi, H.; Shikata, S.I. Characterization of crystallographic defects in homoepitaxial diamond films by synchrotron X-ray topography and cathodoluminescence. Diam. Relat. Mater. 2011, 20, 523-526. [CrossRef]

16. Schreck, M.; Schury, A.; Hörmann, F.; Roll, H.; Stritzker, B. Mosaicity reduction during growth of heteroepitaxial diamond films on iridium buffer layers: Experimental results and numerical simulations. J. Appl. Phys. 2002, 91, 676-685. [CrossRef]

17. Wei, Q.; Niu, G.; Wang, R.; Chen, G.; Lin, F.; Zhang, X.; Zhang, Z.; Wang, H.X. Heteroepitaxy of single crystal diamond on Ir buffered KTaO3 (001) substrates. Appl. Phys. Lett. 2021, 119, 092194. [CrossRef]

18. Zaitsev, A.M.; Kosaca, G.; Richarz, B.; Raiko, V.; Job, R.; Fries, T.; Fahrner, W.R. Thermochemical polishing of CVD diamond films. Diam. Relat. Mater. 1998, 7, 1108-1117. [CrossRef]

19. Jiang, X.; Rickers, C. Defect examination of diamond crystals by surface hydrogen-plasma etching. Appl. Phys. Lett. 1999, 75, 3935-3937. [CrossRef]

20. Ichikawa, K.; Kodama, H.; Suzuki, K.; Sawabe, A. Dislocation in heteroepitaxial diamond visualized by hydrogen plasma etching. Thin Solid Films 2016, 600, 142-145. [CrossRef]

21. Gallheber, B.C.; Klein, O.; Fischer, M.; Schreck, M. Propagation of threading dislocations in heteroepitaxial diamond films with (111) orientation and their role in the formation of intrinsic stress. J. Appl. Phys. 2017, 121, 225301. [CrossRef] 
22. Kim, S.W.; Kawamata, Y.; Takaya, R.; Koyama, K.; Kasu, M. Growth of high-quality one-inch free-standing heteroepitaxial (001) diamond on $\left(112^{-} 0\right)$ sapphire substrate. Appl. Phys. Lett. 2020, 117, 202102. [CrossRef]

23. Motzer, C.; Reichling, M. Morphological classification and quantitative analysis of etch pits. J. Appl. Phys. 2010, 108. [CrossRef]

24. Ichikawa, K.; Kodama, H.; Suzuki, K.; Sawabe, A. Effect of stripe orientation on dislocation propagation in epitaxial lateral overgrowth diamond on Ir. Diam. Relat. Mater. 2017, 72, 114-118. [CrossRef]

25. Washington, M.A.; Cummins, H.Z. Linewidth of the sharp two-phonon Raman peak in diamond. Phys. Rev. B 1977, 15, 5840-5842. [CrossRef]

26. Mehmel, L.; Issaoui, R.; Brinza, O.; Tallaire, A.; Mille, V.; Delchevalrie, J.; Saada, S.; Arnault, J.C.; Bénédic, F.; Achard, J. Dislocation density reduction using overgrowth on hole arrays made in heteroepitaxial diamond substrates. Appl. Phys. Lett. 2021, 118, 061901. [CrossRef]

27. Ferrari, A.C.; Robertson, J. Origin of the $1150-\mathrm{cm}^{-1}$ Raman mode in nanocrystalline diamond. Phys. Rev. B-Condens. Matter Mater. Phys. 2001, 63, 121405. [CrossRef]

28. Prawer, S.; Nemanich, R.J. Raman spectroscopy of diamond and doped diamond. Philos. Trans. R. Soc. A Math. Phys. Eng. Sci. 2004, 362, 2537-2565. [CrossRef] 